\title{
Object-based Land Cover Change Detection and Landscape Structure Analysis of Demilitarized Zone in Korea
}

\author{
Jeongmook Park, Woodam Sim, Jinwoo Park, and Jungsoo Lee* \\ Department of Forest Management, Kangwon National University, Chuncheon 24341, Republic of Korea
}

(Received May 14, 2019; accepted September 9, 2019)

Keywords: demilitarized zone (DMZ), landsat image, object-based classification, land cover change, landscape structure analysis

The demilitarized zone (DMZ) in Korea, a 4-km-wide military-free zone at the border between South Korea and North Korea, has been well preserved for half a century and has a high ecological value. However, temporal and spatial data are lacking owing to poor accessibility. In this study, we detected object-based land cover changes using Landsat-5 TM, Landsat-7 ETM, and Landsat-8 OIS, and identified changes around the DMZ through landscape structure analysis. The land cover was classified into six categories, namely, settlements, cropland, wetlands, forest land, semiforest land, and bare land by object-based classification. The landscape structure was analyzed using five landscape metrics [i.e., number of patches (NumP), mean patch size (MPS), total edge (TE), edge density (ED), and area-weighted mean shape index (AWMSI)]. Results showed that, from 2000 to 2009, the forest land and bare land areas decreased, while the semiforest land area increased. In 2009-2019, the bare land area increased, while the forest land area decreased. Consequently, the restoration of wildfiredamaged areas decreased the fragmentation of Goseong-gun in 2000-2009 and wildfire caused more forest damage in 2009-2019.

\section{Introduction}

According to the Korean War Armistice, the demilitarized zone (DMZ) is an area that measures $2 \mathrm{~km}$ north and $2 \mathrm{~km}$ south of the border between North Korea and South Korea, which is known as the Civilian Control Line (CCL). It was classified by the Special Act on Balanced National Development as an "area requiring special support" and there is limited development in the DMZ. Therefore, the border area's aboriginality, ecosystem, and natural resources have been greatly preserved for more than half a century. This area, therefore, is considered to be an area with a high ecological value worldwide. ${ }^{(1)}$ Thus, the Korea Forest Service founded the North CCL National Forest Management Division in February 2012 and enacted the Special Act on the Management of Forests North of the CCL in April of the same year. In addition, it established laws and organizational systems to manage the forests north of the CCL. Recently, however, owing to the area's inaccessibility and the existence of an 
army camp, artificial forest destruction has occurred. In addition, the effects of recent weather changes and natural disasters, such as localized heavy rain, wildfire, and landslide, have hastened the destruction. Moreover, there is insufficient chronological and special data on the area north of the CCL, and because of the special nature of the area, it is difficult to access this area for field research. ${ }^{(2)}$

Remote sensing is currently playing an important role in research, particularly in the analysis of vegetation and land use changes north of the CCL. Since the late 1990s, the study of CCL using remote exploration techniques developed by Seo and Jeon ${ }^{(1)}$ has been conducted to determine the vegetation and land cover in the north of the CCL using geographic information system (GIS) methods and remote sensing. Kim and Jeong ${ }^{(3)}$ evaluated the ecology of the DMZ using normalized difference vegetation indexes (NDVIs) taken from Landsat-5 TM satellite images. Seo and Park ${ }^{(2)}$ classified landforms using data from high-resolution images, numerical maps, and field research, while $\mathrm{Kim}^{(4)}$ analyzed land cover changes using the DMZ's timeseries data and linear spectral mixture analysis. Choi et al. ${ }^{(5)}$ conducted change detection and land cover classification using medium-resolution satellite images. In the Republic of Korea, Landsat images are used to study land cover changes in the inaccessible DMZ area. ${ }^{(6)}$ Up to now, most research studies on land cover changes had involved classification using the spectral characteristics of pixels. Such research studies merely explain the spatial changes and structural patterns of land cover and cannot fully explain quantitatively the components of the space and aspects of structural transition. At present, segment-based classification, which classifies groups that have been segmented by image segmentation, is being used more frequently in land cover classification and change detection. ${ }^{(7)}$ Unlike object-based classification, it considers scale, spectral information, spatial information, smoothness, and density, which is advantageous because it allows for improved classification accuracy and classification based on each object's characteristics. ${ }^{(8)}$ In addition, landscape structure analysis, which utilizes vegetation and landscape metrics [number of patches (NumP), mean patch size (MPS), total edge (TE), edge density (ED), and area weighted mean shape index], is used to quantitatively assess forest landscape changes, and it has recently been used to analyze landscape ecology changes due to the development of border areas. ${ }^{(9-12)}$ The landscape structure analysis of forest makes it possible to quantitatively express a forest phenomenon divided into two, and it can also explain the decrease in the forest area. ${ }^{(12,13)}$ Therefore, the objective of this study is to analyze the temporal landscape structure of land cover using landscape metrics after classifying the different types of land cover around the DMZ in Goseong-gun on the basis of Landsat-7 ETM+, Landsat-5 TM, and Landsat-8 OIS images at three points in time and by an object-based classification technique.

\section{Materials and Methods}

\subsection{Study area}

The study area is the DMZ in Goseong-gun in Gangwon Province (Fig. 1), where the natural heritage value and natural ecosystem are highly likely to be preserved. The subject area of 


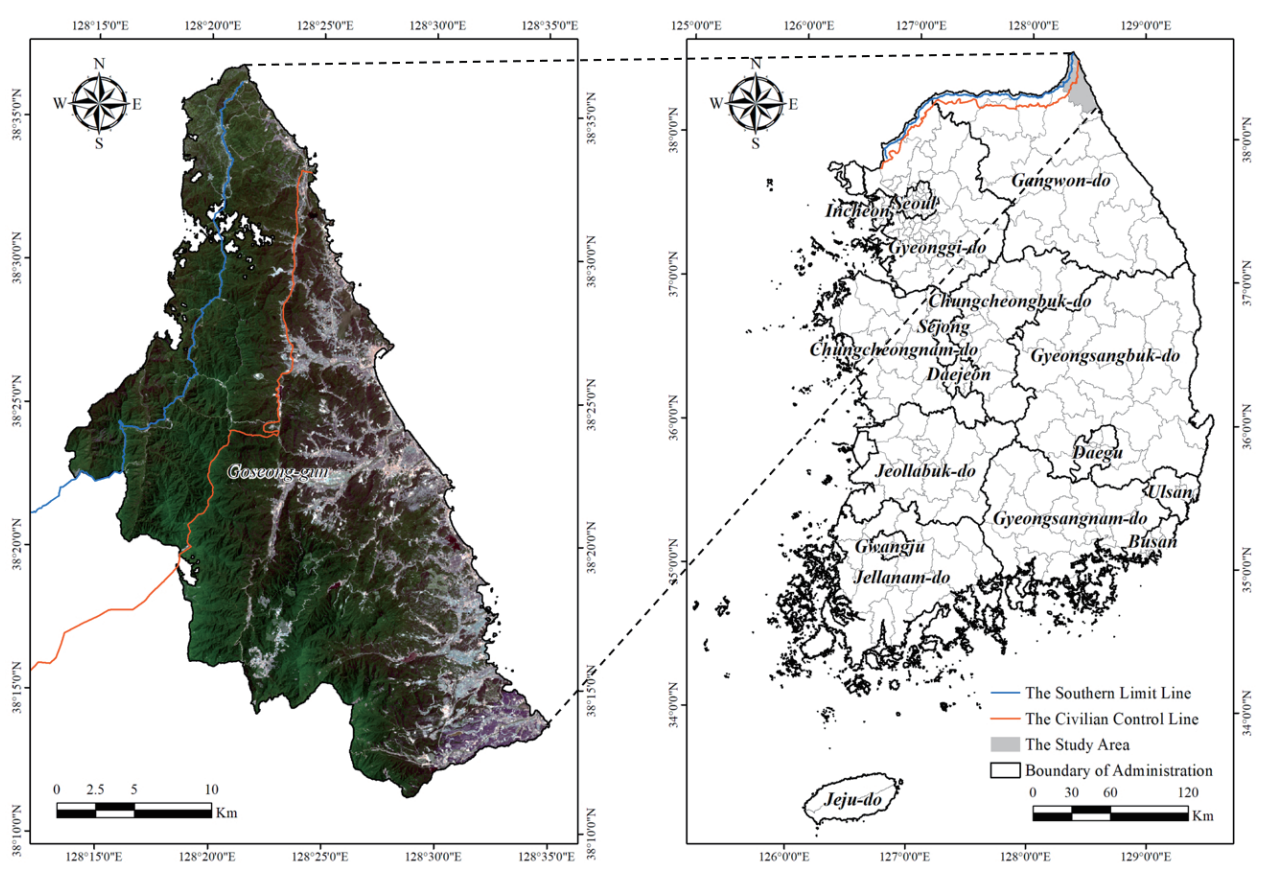

Fig. 1. (Color online) Location of study area.

approximately 63861 ha is the total area of Goseong-gun. It is divided into the north and south parts, with the CCL as its boundary. The regional topography has the typical characteristics of the Youngdong area of Gangwon Province: Its western region is elevated, and its eastern region is low with the hilly sections of the Hyangnobong area located more than $1000 \mathrm{~m}$ high to the west and coastal lowlands of less than $100 \mathrm{~m}$ to the east.

\subsection{Materials}

Landsat-7 ETM+ (2000), Landsat-5 TM (2009), and Landsat-8 OIS (2019) images (Table 1) were used for the object-based classification in our study area. The Landsat images were selected at the same time considering seasonal factors and downloaded by the United States Geological Survey (USGS). The Landsat images were acquired in May, which is the time of planting. Cropland and bare land are well distinguished in May.

GIS information was used for the administrative district map $(1: 25,000)$ provided by the Forest Service and city office. Moreover, eCognition and ArcGIS version 10.1 were used for image analysis, and the 'patch analysis' tool of ArcGIS 10.1 was used for fragmentation analysis.

\subsection{Method}

The research method is presented in Fig. 2. Since none of the pixels were located on the coordinates of the Metacartor chart, spatial distortion occurred; preprocessing is needed owing to errors that may occur when classifying the land cover. 
Table 1

Satellite images used for object-based classification.

\begin{tabular}{lccc}
\hline Satellite type & Sensor & Spatial resolution $(\mathrm{m})$ & Observation date \\
\hline Landsat 7 & ETM+ & 30 & 8 May 2000 \\
Landsat 5 & TM & 30 & 25 May 2009 \\
Landsat 8 & OIS & 30 & 21 May 2019 \\
\hline
\end{tabular}

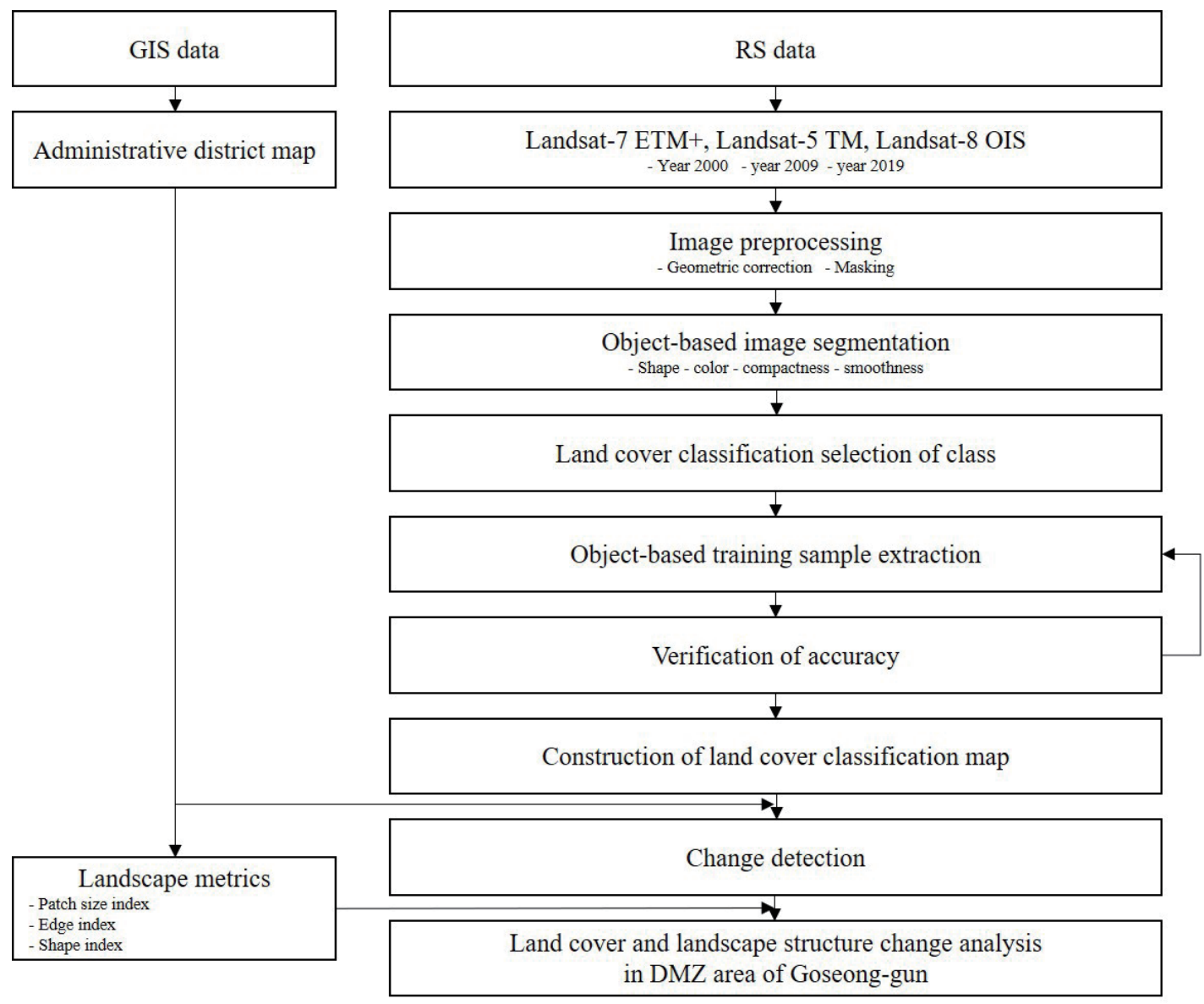

Fig. 2. Framework of study.

Therefore, to match the coordinates exactly with the coordinates on the flat surface, imageto-map and image-to-image geometric corrections were performed. A 2009 Landsat-5 TM image was projected with the Universal Transverse Mercator (UTM) (WGS 84 North Zone 52) using digital and political maps, and the images from 2000 and 2019 were geometrically corrected on the basis of the 2009 image using the image-to-image technique. In addition, because analytical errors can occur owing to clouds in the atmosphere and shadowy regions in the image from 2000, masking was carried out on the clouds and shadows by adjusting the threshold of the image pixel values. To accurately classify the land cover, these errors were eliminated from the 2000, 2009, and 2019 images. Masking areas were excluded from analysis. 


\subsubsection{Image segmentation technique for object-based analysis}

The pixel-based classification method based on particular spectral information of the satellite image pixel is the mainstream land cover classification method. ${ }^{(8)}$ However, analysis is difficult by this method because objects of the same class exhibit a variety of forms and spectral characteristics. Therefore, the object-based classification method, which uses both the spectral and spatial information on the classification object, was used. Although the strength of objectbased image segmentation lies in creating segmented images using image objects defined as having the same area in shape and spectral information (color), its weakness is that it takes a long time to process the images because this method uses a combination of various weights of scale, shape, color, compactness, and smoothness. ${ }^{(15,16)}$ However, the object-based classification is most effective for distinguishing between forest and other land types. The factors for objectbased classification consist of the scale parameter, shape, and compactness. The percent value assigned to shape and compactness represents the weight given to each parameter. Scale is the minimum size required to identify a particular object; this is an important factor affecting the relative size of polygons. When the scale is large, the size of the object increases, and if the scale is small, the size of the object decreases. The shape is calculated using the number of pixels that constitute the object, and the compactness is calculated on the basis of product of the length and width of the object and divided by the number of pixels inside the object. ${ }^{(17)}$ In addition, to determine the optimal weight, the scale, color, and smoothness levels were divided and compared in three stages (units of 100, 10, and 1) using a trial-and-error approach in which the levels per stage were selected by trial and error. ${ }^{(18-20)}$

To determinate the weights of the image segmentation, object segmentation was performed by classifying the combinations of scale, shape, color, compactness, and smoothness levels of the study area into three stages. By observing the merger per weight changes in each stage, the optimal weight was selected. The merging and detection of objects in forests are difficult because the spectral characteristics of objects and forests are similar. ${ }^{(8)}$ Therefore, the weight for merging and detecting was selected on the basis of bare land, agricultural land, and residential objects of small size and clear spectral characteristics. Scale levels were changed in units of 100 in the first stage, units of 10 in the second stage, and units of 1 in the third stage, and the optimal scale level was thus selected.

In scale level 1, the scale level was reduced owing to the changes occurring in the bare land, cropland, and settlements. In scale level 2, objects were classified into more subdivisions than in scale level 1. To further subdivide the classification of objects, the value of scale parameter was reduced in scale level 3. In scale level 3, the change in an object according to the change in weight was identified, and the parameter weight was determined. Moreover, the weight of the color was 0.2 units in the first stage. In the second stage, it was selected by observing color changes gradually in 0.1 units. The allotted values of scale, shape, and compactness are shown in Table 2.

Lee et al. ${ }^{(8)}$ suggested scales of 10 and 15 , spectral information of 0.9 , spatial information of 0.1 , smoothness of 0.5 , and density of 0.5 as the optimal weight combination for classifying land cover. Therefore, in this study, as in previous studies, scale, color, compactness, and smoothness were used as important factors for object-based image segmentation. 
Table 2

Allotted values of scale, shape, color, compactness, and smoothness.

\begin{tabular}{ccccc}
\hline Scale & Shape & Color & Compactness & Smoothness \\
\hline 100 & 0.1 & 0.9 & 0.4 & 0.6 \\
30 & 0.2 & 0.8 & 0.5 & 0.5 \\
3 & 0.1 & 0.9 & 0.4 & 0.6 \\
\hline
\end{tabular}

\subsubsection{Land cover classification}

The segmented images were classified by object-based classification, and land cover maps of 2000, 2009, and 2019 were constructed. ${ }^{(21)}$ Each segmented image was assigned to a class, making it possible to separate land cover types. ${ }^{(22,23)}$ The classification showed that 2000, 2009, and 2019 images are segmented as 98404, 68308, and 117775 objects, respectively.

The land cover classifications of the Intergovernmental Panel of Climate Change (IPCC) and South Korea's Ministry of Environment were used as the standard, and six classes were selected using reference images from IPCC. ${ }^{(24,25)}$ The standards for the six classification classes were (1) urban and asphalt roads for settlements, (2) fields and paddies for cropland, (3) marshes and swamps for wetlands, (4) coniferous and broadleaf forests with sound growth and development for forest land, and (5) land and unpaved roads for bare land. According to the IPCC and land cover classification standards, (6) semiforest land cannot be classified definitively as either forest or grassland; therefore, forest areas with unstable growth and development with degrees of stocking below $30 \%$ and with low density were used as the classification criteria for semiforest. A brief description of each class is shown in Table 3.

\subsubsection{Accuracy assessment}

A classified image was analyzed for accuracy using the overall accuracy (OA), user's accuracy (UA), producer's accuracy (PA), and Kappa coefficient. Accuracy was assessed using a confusion matrix for 2000, 2009, and 2019 object-based image classifications. Training samples were objects that were selected by referring to Google Earth. At least 50 random samples for each class were used in Goseong-gun to analyze the OA, UA, and PA of the classified image and the Kappa coefficient. Kappa analysis is a separate multivariate method used for evaluating accuracy. It is also used to calculate the statistical value $\hat{k}$ using the values in the rows, columns, and principal diagonal of the confusion matrix, and shows the degree of conformity between the classification map and the reference data. ${ }^{(26,27)} \mathrm{A} \hat{k}$ value greater than 0.8 means that the conformity and accuracy are excellent, and values of $0.6-0.8$ mean that they are good, $0.4-0.6$ average, $0.2-0.4$ below average, and 0.2 and below poor. ${ }^{(27)}$

The OAs of classification were 93, 94, and 95\%, and the Kappa coefficients were 0.91, 0.93, and 0.95 for the 2000, 2009, and 2019 images, respectively. In terms of PA for 2000, the total number of classes was more than $85 \%$. All the categories were classified correctly. UA was more than $90 \%$ except for settlements, which was $83 \%$. The lowest class for PA was bare land for 2009, and the lowest class for UA was settlements. The lowest PA (74\%) corresponded to semiforest land, and the lowest UA (84\%) corresponded to settlements. The settlements were classified as having the lowest UA in 2000 (Tables 4-7). 
Table 3

Descriptions of classes.

\begin{tabular}{lc}
\hline Class & Description \\
\hline $\begin{array}{l}\text { Settlements } \\
\text { Cropland }\end{array}$ & Urban and asphalt roads, all developed land areas, human settlements \\
Wetlands & Fields and paddies, cultivated forest \\
Forest land & Marshes and swamps, reservoir, natural river, lake \\
Semiforest land & Coniferous and broadleaf forests \\
Bare land & Cannot be classified definitively as either forest or grassland \\
\hline
\end{tabular}

Table 4

Confusion matrix for 2000 image classification.

\begin{tabular}{|c|c|c|c|c|c|c|c|}
\hline \multirow{2}{*}{ Class } & \multicolumn{7}{|c|}{ Reference } \\
\hline & Settlements & Cropland & Wetlands & Forest land & Semiforest land & Bare land & Sum \\
\hline Settlements & 149 & 10 & & & 12 & 8 & 179 \\
\hline Cropland & & 114 & & & & & 114 \\
\hline Wetlands & & & 62 & & & & 62 \\
\hline Forest land & & 9 & & 102 & & & 111 \\
\hline Semiforest land & & & & & 82 & & 82 \\
\hline Bare land & & & & & & 47 & 47 \\
\hline Sum & 149 & 133 & 62 & 102 & 94 & 55 & 595 \\
\hline
\end{tabular}

Table 5

Confusion matrix for 2009 image classification.

\begin{tabular}{|c|c|c|c|c|c|c|c|}
\hline \multirow{2}{*}{ Class } & \multicolumn{7}{|c|}{ Reference } \\
\hline & Settlements & Cropland & Wetlands & Forest land & Semiforest land & Bare land & Sum \\
\hline Settlements & 104 & 8 & & & 6 & 12 & 130 \\
\hline Cropland & & 42 & 2 & & & & 44 \\
\hline Wetlands & & & 117 & & & & 117 \\
\hline Forest land & & & & 96 & & & 96 \\
\hline Semiforest land & & & & & 75 & & 75 \\
\hline Bare land & & & & & & 51 & 51 \\
\hline Sum & 104 & 50 & 119 & 96 & 81 & 63 & 513 \\
\hline
\end{tabular}

Table 6

Confusion matrix for 2019 image classification.

\begin{tabular}{|c|c|c|c|c|c|c|c|}
\hline \multirow{2}{*}{ Class } & \multicolumn{7}{|c|}{ Reference } \\
\hline & Settlements & Cropland & Wetlands & Forest land & Semiforest land & Bare land & Sum \\
\hline Settlements & 54 & & & & 7 & & 61 \\
\hline Cropland & & 113 & & & & & 113 \\
\hline Wetlands & & & 73 & & & & 73 \\
\hline Forest land & & & & 106 & 3 & & 109 \\
\hline Semiforest land & & & & & 55 & & 55 \\
\hline Bare land & & & & & 9 & 68 & 77 \\
\hline Sum & 54 & 113 & 73 & 106 & 74 & 68 & 488 \\
\hline
\end{tabular}

Table 7

Results of accuracy assessment along classification method.

\begin{tabular}{lcrrrrr}
\hline \multirow{2}{*}{ Class } & \multicolumn{2}{c}{2000} & \multicolumn{2}{c}{2009} & \multicolumn{2}{c}{2019} \\
\cline { 2 - 7 } & PA (\%) & UA (\%) & PA (\%) & UA (\%) & PA (\%) & UA (\%) \\
\hline Settlements & 96.2 & 93.1 & 88.9 & 80.0 & 100.0 & 93.7 \\
Cropland & 91.4 & 98.0 & 87.3 & 80.3 & 99.3 & 98.4 \\
Wetlands & 98.8 & 100.0 & 100.0 & 100.0 & 84.5 & 100.0 \\
Forest & 99.5 & 93.9 & 100.0 & 95.9 & 95.0 & 96.7 \\
Semiforest land & 87.9 & 86.6 & 78.8 & 99.9 & 94.1 & 83.3 \\
Bare land & 92.8 & 99.3 & 83.5 & 90.3 & 98.1 & 100.0 \\
\hline OA & \multicolumn{7}{c}{94.6} & \multicolumn{2}{c}{96.1} & \multicolumn{2}{c}{95.6} \\
\hline Kappa & 0.91 & 0.93 & \multicolumn{2}{c}{0.95} \\
\hline
\end{tabular}




\subsubsection{Landscape structure analysis using landscape metrics}

Changes were detected by establishing land cover degrees at two time periods using the results of the object-based classification, which has a high classification accuracy. The landscape metrics, which use the shape and area of the patch, were applied to determine landscape structural changes. The landscape structure analysis enables the assessment of the overall characteristic of the object change through the quantification of the landscape structural changes. With regard to evaluation factors, area metrics, patch density, size, edge metrics, shape metrics, diversity and interspersion metrics, and core area metrics are widely used. ${ }^{(28,29)}$ NumP, MPS, TE, ED, and area-weighted mean shape index (AWMSI), which are the most widely used factors for landscape structure analysis using landscape metrics, were applied in this research. ${ }^{(8,11,30)}$

$$
\begin{gathered}
\text { NumP }=n_{i} \\
M P S=\frac{\text { mean }_{i}=\left(a_{i j}\right)}{A} \times 100 \\
T E=\sum_{k=1}^{m} e_{i k} \\
E D=\frac{\sum_{k=1}^{m} e_{i k}}{A} \times 100 \\
A W M S I=\frac{0.25 \sum_{k=1}^{m} e_{i k}}{\sqrt{A}}
\end{gathered}
$$

Here, $n_{i}$ is the total NumP, $a_{i j}$ is the area $\left(m^{2}\right)$ of patch $i j, A$ is the total landscape area $\left(m^{2}\right)$, and $e_{i k}$ is the total length of the edge.

The fluctuation of fragmentation is shown through NumP and the average patch size. Fragmentation increases with NumP and the average patch size decreases. The TE length and ED illustrate the complexity of the patch shape, and as the TE length and ED increase, the form of fragmentation becomes more complex. The landscape weighted-average shape index also expresses the complexity of the patch shape.

\section{Results and Discussion}

\subsection{Land cover classifications in 2000, 2009, and 2019}

In descending order by area, the land cover classification categories in 2000 were forest land, settlements, cropland, bare land, semiforest land, and wetlands, and those in 2009 were forest land, settlements, cropland, semiforest land, bare land, and wetlands. The semiforest 
land area was larger in 2009 than in 2000. The forest land area decreased from 53435 to 50763 ha, while the settlement area increased from 6191 to 7460 ha over 20 years. The forest land and semiforest land areas decreased from 53453 to 50763 ha and 507 to 342.29 ha, respectively, while the bare land and settlement areas respectively increased from 698 to 1107 ha and 6191 to 7460 ha in 2019. The results of this study are similar to those of previous studies on land cover dynamics in the DMZ. The bare land area decreased from 698 to 380 ha, while the semiforest land increased from 507 to 884 ha in the first period (2000-2009). It seems that the semiforest land became bare land as a result of wildfire in 2000 .

The land cover classification categories in 2019 were, in descending order by area, forest land, settlements, cropland, bare land, semiforest land, and wetlands. Compared with the land cover classification categories in 2009, the bare land area increased from 380 to 1107 ha. In April 2019, wildfires occurred in Goseong-gun, resulting in the increase in the bare land area. The forest land area decreased continuously from 2000 to 2019. Forest land made up more than $75 \%$ of the total area over 20 years. Forest land seems to account for more than $90 \%$ of the total land area north of the CCL. The bare land area temporarily decreased in the first period (2000-2009), but it increased in the second period (2009-2019). The settlement area has been steadily increasing since 2000. This is attributed to large wildfires that occurred in April 2019. South of the CCL, the forest land area decreased to approximately 2000 ha over 20 years, while the bare land area decreased to 209 ha in the first period (2000-2009) and increased to 622 ha in the second period (2009-2019).

The forest land area has been continuously decreasing for 20 years, which is attributed to large wildfires, damage, and development in 2000 and 2019. In this study, we can detect land cover changes by period. The detection of forest land change will help establish forest management and forest protection plans (Table 8).

\subsection{Land cover classifications in 2000, 2009, and 2019}

As for the area change per class between 2000 and 2009, 4\% of forest land in 2000 changed to settlements and $2 \%$ to cropland. Moreover, $34 \%$ of bare land changed to forest land and $32 \%$ to settlements. The changes in these areas seem to be a result of wildfires that occurred in the early 2000s. Also, 60\% of semiforest land changed to forest land (Fig. 3 and Table 9).

Between 2009 and 2019, 4\% of forest land changed to settlements. Moreover, 54\% of semiforest land changed to forest land and $32 \%$ to settlements.

Table 8

Changes in land cover.

\begin{tabular}{lcccccc}
\hline \multirow{2}{*}{ Class } & \multicolumn{2}{c}{2000} & \multicolumn{2}{c}{2009} & \multicolumn{2}{c}{2019} \\
\cline { 2 - 7 } & Area (ha) & Ratio (\%) & Area (ha) & Ratio (\%) & Area (ha) & Ratio (\%) \\
\hline Settlements & 6191 & 9.8 & 6253 & 9.7 & 7460 & 11.6 \\
Cropland & 2785 & 4.4 & 3876 & 6 & 3797 & 4.9 \\
Wetlands & 224 & 0.4 & 291 & 0.5 & 391 & 0.9 \\
Forest & 53453 & 83.7 & 52176 & 81.7 & 50763 & 80.4 \\
Semiforest land & 507 & 0.7 & 885 & 1.4 & 342 & 0.5 \\
Bare land & 698 & 1 & 380 & 0.7 & 1108 & 1.7 \\
Total & 63861 & 100 & 63861 & 100 & 63861 & 100 \\
\hline
\end{tabular}



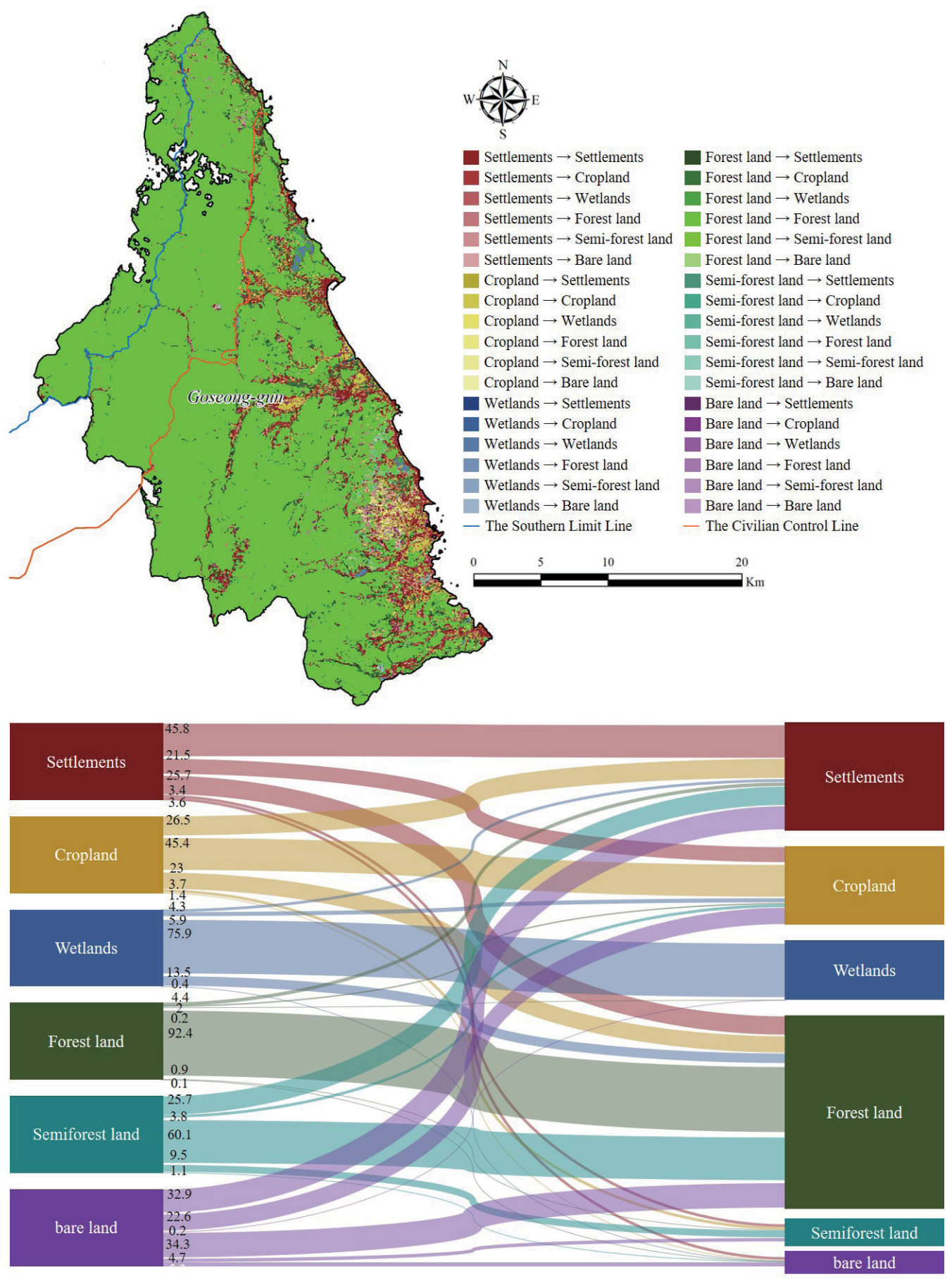

Fig. 3. (Color online) Maps of land cover change obtained by classification (2000-2009).

Between 2000 and 2019, 35\% of bare land changed to forest land and 37\% changed to settlements. Also, $61 \%$ of semiforest land changed to forest land, indicating that forest destruction and recovery occurred simultaneously in Goseong-gun.

As for the land cover change patterns north and south of the CCL, in the case of forest land, the rate of change to bare land was 6 times higher in the south than in the north, and the rates of change to settlements and cropland were 9.6 and 2.4 times higher in the south, respectively. 
Table 9

Transition matrix describing land cover changes between 2000 and 2009.

\begin{tabular}{|c|c|c|c|c|c|c|c|c|c|}
\hline \multirow{2}{*}{\multicolumn{3}{|c|}{ Classification }} & \multicolumn{7}{|c|}{2009} \\
\hline & & & \multirow{2}{*}{$\begin{array}{c}\text { Settlements } \\
45.8\end{array}$} & \multirow{2}{*}{$\begin{array}{c}\text { Cropland } \\
21.5\end{array}$} & \multirow{2}{*}{ Wetlands } & \multirow{2}{*}{$\begin{array}{c}\begin{array}{c}\text { Forest } \\
\text { land }\end{array} \\
25.7\end{array}$} & \multirow{2}{*}{$\begin{array}{c}\text { Semiforest } \\
\text { land }\end{array}$} & \multirow{2}{*}{$\begin{array}{c}\text { Bare land } \\
3.6\end{array}$} & \multirow{2}{*}{$\begin{array}{r}\text { Total } \\
100\end{array}$} \\
\hline \multirow{21}{*}{2000} & \multirow{7}{*}{$\begin{array}{l}\text { Total } \\
\text { area }\end{array}$} & Settlements & & & & & & & \\
\hline & & Cropland & 26.5 & 45.4 & & 23.0 & 3.7 & 1.4 & 100 \\
\hline & & Wetlands & 4.3 & 5.9 & 75.9 & 13.5 & & 0.4 & 100 \\
\hline & & Forest land & 4.4 & 2.0 & 0.2 & 92.4 & 0.9 & 0.1 & 100 \\
\hline & & $\begin{array}{l}\text { Semiforest } \\
\text { land }\end{array}$ & 25.7 & 3.8 & & 60.1 & 9.5 & 1.1 & 100 \\
\hline & & Bare land & 32.9 & 22.6 & 0.2 & 34.3 & 4.7 & 5.3 & 100 \\
\hline & & Total & 9.7 & 4.4 & 0.4 & 83.8 & 0.7 & 1.0 & 100 \\
\hline & \multirow{7}{*}{$\begin{array}{c}\text { North } \\
\text { of } \\
\text { CCL }\end{array}$} & Settlements & 36.8 & 6.9 & & 47.2 & 7.5 & 1.6 & 100 \\
\hline & & Cropland & 41.5 & 19.8 & & 29.9 & 5.4 & 3.4 & 100 \\
\hline & & Wetlands & 2.6 & - & 26.5 & 70.9 & - & - & 100 \\
\hline & & Forest land & 2.2 & & 0.3 & 96.6 & 0.6 & 0.3 & 100 \\
\hline & & $\begin{array}{l}\text { Semiforest } \\
\text { land }\end{array}$ & 44.0 & 3.7 & & 33.5 & 16.6 & 2.2 & 100 \\
\hline & & Bare land & 30.2 & 3.3 & & 55.2 & 8.2 & 3.1 & 100 \\
\hline & & Total & 3.3 & 0.6 & & 95.3 & 0.1 & 0.7 & 100 \\
\hline & \multirow{7}{*}{$\begin{array}{c}\text { South } \\
\text { of } \\
\text { CCL }\end{array}$} & Settlements & 46.9 & 23.4 & & 22.8 & 3.0 & 3.9 & 100 \\
\hline & & Cropland & 25.7 & 46.4 & & 22.8 & 3.7 & 1.4 & 100 \\
\hline & & Wetlands & 4.3 & 6.2 & 77.3 & 11.7 & & 0.5 & 100 \\
\hline & & Forest land & 5.7 & 3.2 & 0.3 & 89.5 & 1.2 & 0.1 & 100 \\
\hline & & Semiforest land & 24.4 & 3.6 & & 61.9 & 9.1 & 1.0 & 100 \\
\hline & & Bare land & 33.5 & 27.2 & 0.3 & 29.2 & 3.9 & 5.9 & 100 \\
\hline & & Total & 13.0 & 6.3 & 0.6 & 77.5 & 1.2 & 1.4 & 100 \\
\hline
\end{tabular}

Rate of change (\%)

Also, south of the CCL, the rates of change to settlements from forest land and semiforest were 2 and 3.6 times lower than in the north, respectively. On the other hand, Kim and Jeong ${ }^{(3)}$ found that the DMZ is being damaged each year by incineration in the army camps and wildfires moving south from the north; Goseong-gun suffered serious damage from a major wildfire in 2000. North of the CCL, the forest land was maintained at a higher ratio than south of the CCL. On the other hand, $5 \%$ of forest land south of the CCL changed to settlements in both periods (2000-2009 and 2009-2019), indicating greater forest damage south of the CCL (Fig. 4 and Table 10).

\subsection{Landscape structure analysis of DMZ}

MPS of forest land and settlements increased and NumP decreased. Land cover shape became simplified as TE and ED decreased in the first period (2000-2009). In the second period (2009-2019), MPS and NumP of forest land, settlements, and cropland decreased, while ED increased, indicating that the fragmentation of land cover progressed in the second period (2009-2019), unlike in the first period (2000-2009).

As many patches of cropland merged thereby decreasing NumP, MPS of the land cover increased. As TE and ED of patches decreased, the complexity of land cover shape increased. Similarly to cropland, the patches of forest land merged; thus, MPS of land cover increased, and the land cover shape was simplified, as indicated by the decreases in TE and ED. In particular, the results of this study were consistent with those obtained by Lee et al. ${ }^{(31)}$ The results showed 

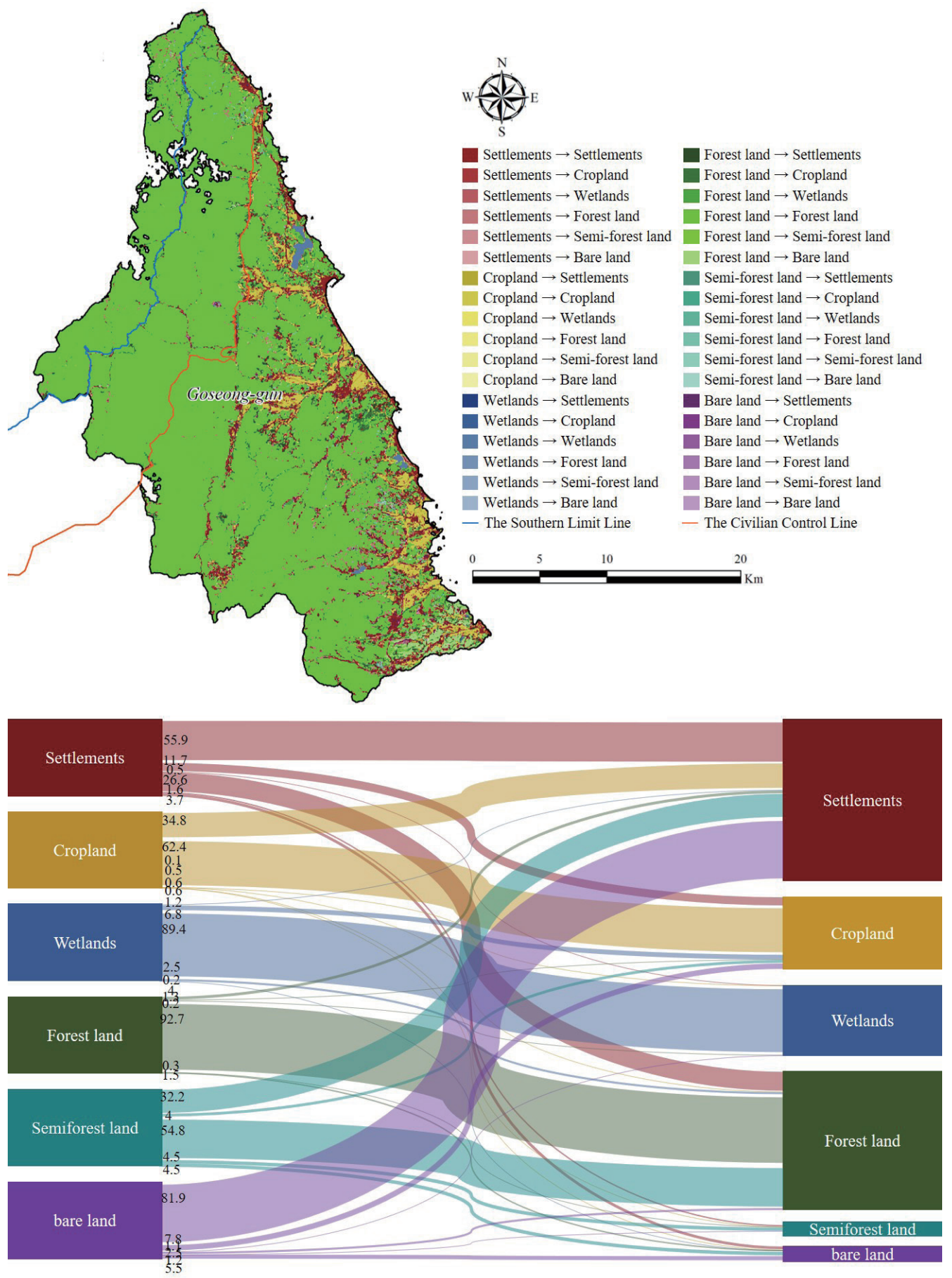

Fig. 4. (Color online) Maps of land cover change obtained by classification (2009-2019).

that the fragmentation decreased because the NumP values of cropland, forest land, and semiforest land decreased with time, as did TE and ED. By comparing the landscape structures in the north and south areas of the CCL, it is evident that in the north area, fragmentation decreased, NumP decreased, and the average patch size increased in cropland, forest land, and settlements in the first period (2000-2009) (Table 11). 
Table 10

Transition matrix describing land cover changes between 2009 and 2019.

\begin{tabular}{|c|c|c|c|c|c|c|c|c|c|}
\hline \multirow{2}{*}{\multicolumn{2}{|c|}{ Classification }} & & \multicolumn{7}{|c|}{2019} \\
\hline & & & Settlements & Cropland & Wetlands & Forest & Semiforest & Bare land & Total \\
\hline \multirow{21}{*}{2009} & \multirow{7}{*}{$\begin{array}{l}\text { Total } \\
\text { area }\end{array}$} & Settlements & 55.9 & 11.7 & 0.5 & 26.6 & 1.6 & 3.7 & 100 \\
\hline & & Cropland & 34.8 & 62.4 & 0.6 & 0.5 & 0.1 & 1.6 & 100 \\
\hline & & Wetlands & 1.2 & 6.8 & 89.4 & 2.5 & & 0.2 & 100 \\
\hline & & Forest land & 4.0 & 1.3 & 0.2 & 92.7 & 0.3 & 1.5 & 100 \\
\hline & & $\begin{array}{l}\text { Semiforest } \\
\text { land }\end{array}$ & 32.2 & 4.0 & & 54.8 & 4.5 & 4.5 & 100 \\
\hline & & Bare land & 81.9 & 7.8 & 1.1 & 2.5 & 1.2 & 5.5 & 100 \\
\hline & & Total & 9.8 & 6.0 & 0.5 & 81.8 & 1.3 & 0.6 & 100 \\
\hline & \multirow{7}{*}{$\begin{array}{c}\text { North } \\
\text { of } \\
\text { CCL }\end{array}$} & Settlements & 43.4 & 5.0 & 0.2 & 43.5 & 2.9 & 5.0 & 100 \\
\hline & & Cropland & 45.0 & 27.7 & 0.3 & 24.2 & 0.9 & 1.9 & 100 \\
\hline & & Wetlands & 19.5 & 13.8 & 58.3 & 2.8 & - & 5.6 & 100 \\
\hline & & Forest land & 2.2 & 0.5 & & 96.7 & 0.3 & 0.3 & 100 \\
\hline & & $\begin{array}{l}\text { Semiforest } \\
\text { land }\end{array}$ & 34.4 & 1.7 & & 55.8 & 2.9 & 5.2 & 100 \\
\hline & & Bare land & 83.4 & 2.3 & & 2.3 & & 12.0 & 100 \\
\hline & & Total & 3.8 & 0.7 & & 94.4 & 0.9 & 0.2 & 100 \\
\hline & \multirow{7}{*}{$\begin{array}{c}\text { South } \\
\text { of } \\
\text { CCL }\end{array}$} & Settlements & 57.9 & 12.8 & 0.5 & 23.8 & 1.5 & 3.5 & 100 \\
\hline & & Cropland & 31.5 & 59.4 & 0.7 & 6.6 & 0.3 & 1.5 & 100 \\
\hline & & Wetlands & 1.0 & 6.9 & 89.6 & 2.4 & & 0.1 & 100 \\
\hline & & Forest land & 5.4 & 2.0 & 0.3 & 89.9 & 0.3 & 2.1 & 100 \\
\hline & & Semiforest land & 31.5 & 4.8 & & 54.6 & 4.9 & 4.2 & 100 \\
\hline & & Bare land & 81.9 & 8.2 & 1.2 & 2.5 & 1.3 & 4.9 & 100 \\
\hline & & Total & 12.9 & 8.9 & 0.7 & 75.0 & 1.6 & 0.9 & 100 \\
\hline
\end{tabular}

Rate of change (\%)

Table 11

Analysis of fragmentation in 2000-2009.

\begin{tabular}{|c|c|c|c|c|c|c|c|}
\hline & & $\begin{array}{c}\text { Area } \\
\text { (ha) }\end{array}$ & $\begin{array}{c}\text { MPS } \\
\text { (number) }\end{array}$ & $\begin{array}{l}\text { MPS } \\
\text { (ha) }\end{array}$ & $\begin{array}{l}\mathrm{TE} \\
(\mathrm{km})\end{array}$ & ED & $\begin{array}{c}\text { Area-weighted } \\
\text { mean shape index }\end{array}$ \\
\hline \multirow{6}{*}{ Total area } & Settlements & 61 & -5247 & 0.11 & -4.56 & -7.10 & 0.000 \\
\hline & Cropland & 1090 & -525 & 0.16 & 4.43 & 6.90 & 0.000 \\
\hline & Wetlands & 66 & -847 & 0.03 & 0.05 & 0.09 & -0.020 \\
\hline & Forest land & -1277 & -23650 & 0.42 & -48.81 & -76.40 & -0.010 \\
\hline & Semiforest land & 377 & 245 & 0.18 & 2.00 & 3.20 & 0.000 \\
\hline & Bare land & -318 & -847 & -0.03 & -2.40 & -3.70 & 0.000 \\
\hline \multirow{6}{*}{$\begin{array}{l}\text { North of } \\
\text { CCL }\end{array}$} & Settlements & 131 & -434 & 0.16 & 0.10 & 0.87 & -0.009 \\
\hline & Cropland & 17 & -135 & 0.14 & 0.12 & 5.12 & 0.001 \\
\hline & Wetlands & -3 & 0 & -0.43 & 0.01 & -0.07 & 0.000 \\
\hline & Forest land & -211 & -9963 & 0.50 & -20.00 & -94.80 & -0.010 \\
\hline & Semiforest land & 174 & 194 & 0.39 & -0.01 & 4.74 & 0.000 \\
\hline & Bare land & -108 & -273 & -0.06 & -0.80 & -3.64 & -0.006 \\
\hline \multirow{6}{*}{$\begin{array}{l}\text { South of } \\
\text { CCL }\end{array}$} & Settlements & -70 & -4840 & 0.00 & 40.00 & 2.00 & 0.000 \\
\hline & Cropland & 1072 & -376 & 2.00 & -15.00 & -1.00 & -0.005 \\
\hline & Wetlands & 70 & 37 & -5.00 & 52.00 & 3.00 & -0.020 \\
\hline & Forest land & -1065 & -13790 & -29.00 & 270.00 & 16.00 & -0.010 \\
\hline & Semiforest land & 202 & 65 & 0.30 & -76.00 & -5.00 & 0.000 \\
\hline & Bare land & -209 & -581 & -2.00 & 284.00 & 17.00 & -0.006 \\
\hline
\end{tabular}

NumP decreased and the average size increased in cropland, forest land, and settlements south of the CCL, leading to decreased fragmentation. Settlements, cropland, wetland, forest land, and bare land showed an increase in NumP, while MPS decreased, and this caused an increase in fragmentation. Suh and $\mathrm{Kim}^{(32)}$ and Jung et al. ${ }^{(33)}$ reported that highly fragmented 
Table 12

Analysis of fragmentation in 2009-2019.

\begin{tabular}{|c|c|c|c|c|c|c|c|}
\hline & & $\begin{array}{c}\text { Area } \\
\text { (ha) }\end{array}$ & $\begin{array}{c}\text { Number of } \\
\text { patches (number) }\end{array}$ & $\begin{array}{l}\text { MPS } \\
\text { (ha) }\end{array}$ & $\begin{array}{c}\text { TE } \\
(\mathrm{km})\end{array}$ & ED & $\begin{array}{c}\text { Area-weighted } \\
\text { mean shape index }\end{array}$ \\
\hline \multirow{6}{*}{ Total area } & Settlements & 1207 & 20003 & -0.21 & 23.37 & 36.59 & 0.00 \\
\hline & Cropland & -79 & 5601 & -0.22 & 4.89 & 7.67 & 0.00 \\
\hline & Wetlands & 98 & 253 & -0.69 & 1.03 & 1.61 & 0.00 \\
\hline & Forest land & -1412 & 21448 & -0.43 & 48.54 & 76.01 & 0.00 \\
\hline & Semiforest land & -542 & -419 & -0.26 & -3.08 & -4.82 & 0.00 \\
\hline & Bare land & 727 & 2343 & 0.00 & 5.76 & 9.04 & 0.00 \\
\hline \multirow{6}{*}{$\begin{array}{l}\text { North of } \\
\text { CCL }\end{array}$} & Settlements & 136 & 2519 & -0.26 & 2.98 & 13.53 & 0.00 \\
\hline & Cropland & 32 & 377 & -0.16 & 0.44 & 2.04 & 0.00 \\
\hline & Wetlands & 7 & 35 & -0.16 & 0.06 & 0.31 & 0.00 \\
\hline & Forest land & -166 & 8494 & -0.47 & 22.37 & 101.63 & 0.00 \\
\hline & Semiforest land & -114 & 29 & -0.37 & -0.52 & -2.40 & 0.00 \\
\hline & Bare land & 105 & 472 & -0.08 & 0.94 & 4.29 & 0.00 \\
\hline \multirow{6}{*}{$\begin{array}{l}\text { South of } \\
\text { CCL }\end{array}$} & Settlements & 1071 & 17654 & -0.20 & 20.43 & 48.96 & 0.01 \\
\hline & Cropland & -111 & 5249 & -0.22 & 4.41 & 10.58 & 0.00 \\
\hline & Wetlands & 91 & 223 & -0.70 & 0.97 & 2.33 & 0.07 \\
\hline & Forest land & -1246 & 12979 & -0.40 & 26.11 & 62.56 & 0.03 \\
\hline & Semiforest land & -427 & -455 & -0.23 & -2.58 & -6.19 & 0.01 \\
\hline & Bare land & 622 & -581 & 0.01 & 4.83 & 11.58 & 0.01 \\
\hline
\end{tabular}

forest land has a high absorption potential for alternate uses, and with fragmentation accelerating, there cannot be a stable, sound landscape structure for forest land. This is consistent with the aspect of fragmentation in the whole area of Goseong-gun, indicating that fragmentation decreased both north and south of the CCL from 2000 to 2009 and increased after 2009. This analysis will help establish an overall forest management plan and will be useful for forest restoration and management in the future (Table 12).

\section{Conclusions}

In Goseong-gun, two of the largest wildfires occurred in 2000 and 2019. Owing to the effects of these wildfires, the bare land area was higher in 2000 and 2019 than in 2009. In 2000 , much of the bare land was changed to forest land and settlements. It was determined that forest conservation and regional restoration occurred simultaneously in Goseong-gun. Most of the bare land changed to settlements from 2009 owing to the development north of the CCL. In addition, the decrease in bare land area and the increase in semiforest land area in the first period (2000-2009) appeared to be reversed after the wildfire, and the increase in bare land area and the decrease in forest and semiforest land areas in the second period (2009-2019) were determined to be due to the large wildfire that occurred in 2019.

Although it was considered that the landscape structure regarding land cover and land use would be simple because access to the DMZ has been restricted for the past 60 years, the results of this study showed that forest destruction and development continued owing to urbanization and wildfires. In this study, we identified the land cover changes and characteristics of the DMZ of Goseong-gun, which has poor accessibility, through object-based land cover classification. The land cover was analyzed in various aspects by landscape structure analysis. 
We consider that the future development and destruction of the forest landscape can be assessed using the results of the objective analysis in this research. Moreover, the results of this study can be used as important baseline data to establish a regional development strategy. Furthermore, these results can also be used to monitor the management of specific areas.

\section{Acknowledgments}

This study was carried out with the support of the R\&D Program for Forest Science Technology '(Project No. 2017045A00-1919-BB01)' provided by Korea Forest Service (Korea Forestry Promotion Institute).

\section{References}

1 C. W. Seo and S. W. Jeon: J. Environ. Impact Assess. 7 (1998) 11. http://kiss.kstudy.com/thesis/thesis-view. asp?key $=165535$

2 J. C. Seo and K. A. Park: J. KARG 9 (2003) 385. http://www.dbpia.co.kr/journal/ articleDetail?nodeId $=$ NODE02494531\&language $=$ ko KR

3 S. W. Kim and J. C. Jeong: J. KAGIS 5 (2002) 24. http://kiss.kstudy.com/thesis/thesis-view.asp?key=1990668

4 S. W. Kim: J. KAGIS 9 (2006) 95. http://kiss.kstudy.com/thesis/thesis-view.asp?key=2581728

5 B. G. Choi, J. M. Park, and J. S. Lee: JAKPG 23 (2013) 1. https://doi.org/10.35149/jakpg.2013.23.1.007

6 H. C. Park, J. C. Lim, J. H. Lee, and G. G. Lee: J. KOSERT 20 (2017) 1. https://doi.org/10.13087/ kosert.2017.20.1.1

7 S. Y. Chung, J. S. Yim, and M. Y. Shin: J. Korean Forest Soc. 100 (2011) 540. http://kiss.kstudy.com/thesis/ thesis-view.asp?key=2972991

8 H. J. Lee, J. H. Ru, and S. H. Kim: J. Korean Soc. Geo. Inf. Sci. 19 (2011) 105. http://www.dbpia.co.kr/journal/ articleDetail?nodeId=NODE01625716\&language $=$ ko_KR

9 S. W. Kim and J. H. Park: J. Environ. Impact Assess. 10 (2001) 39. http://kiss.kstudy.com/thesis/thesis-view. asp?key $=1726684$

10 M. Herold and J. Scepan: Environ. Plan. A 34 (2002) 1443. https://doi.org/10.1068/a3496

11 C. Y. Sung and W. Cho: Korean J. Environ. Ecol. 26 (2012) 952. http://www.envecojournal.org/journal/article. php?code $=7394$

12 C. R. Fichera, G. Modica, and M. Pollino: Eur. J. Remote Sens. 45 (2012) 1. https://doi.org/10.5721/ EuJRS20124501

13 J. Peng, Y. Wang, Y. Zhang, J. Wu, W. Li, and Y. Li: Ecol. Indic. 10 (2010) 217. https://doi.org/10.1016/ j.ecolind.2009.04.017

14 E. Y. Kim, W. K. Song, and D. K. Lee: KOSERT 15 (2012) 149. https://doi.org/10.13087/kosert.2012.15.2.149

15 J. B. Lee, J. Heo, and Y. D. Eo: Korean J. Remote Sens. 23 (2007) 521. http://kiss.kstudy.com/thesis/thesisview.asp?key $=2798049$

16 K. Johnsson: Photogramm. Eng. Remote Sen. 61 (1994) 47. https://www.asprs.org/wp-content/uploads/ pers/1994journal/jan/1994_jan_47-53.pdf

17 T. Rittl, M. Cooper, R. J. Heck, and M. V. R. Ballester: Pedosphere 23(3) 290. https://doi.org/10.1016/S10020160(13)60018-1

18 J. B. T. M. Roerdink and A. Meijster: Fund. Inf. 41 (2000) 187. https://dl.acm.org/citation.cfm?id=2372495

19 S. W. Kim: Master's thesis, Korea University (2003).

20 W. M. Soe, P. Gober, A. Brazel, S. Grossman-Clarke, and Q. Weng: Remote Sens. Environ. 115 (2011) 1145. https://doi.org/10.1016/j.rse.2010.12.017

21 M. Kindu, T. Schneider, D. Teketay and T. Knoke: Remote Sens. 5 (2013) 5. https://doi.org/10.3390/rs5052411

22 V. Walter: J. Photogramm. Remote Sens. 58 (2004) 225. https://doi.org/10.1016/j.isprsjprs.2003.09.007

23 W. Chaofan, D. Jinsong, W. Ke, M. Ligang, and A. R. S. Tahmassebi: Int. J. Agric. Biol. Eng. 9 (2016) 1. 10.3965/j.ijabe.20160901.1414

24 S. Eggleston, L. Buendia, K. Miwa, T. Ngara, and K. Tanabe: 2006 IPCC Guidelines for National Greenhouse Gas Inventories Volume 4 (IPCC, Geneva, 2006) p. 1.17.

25 Ministry of Environment: https://egis.me.go.kr (accessed March 2017). 
26 R. G. Congalton and R. A. Mead: Photogamm. Eng. Remote Sen. 49 (1983) 69. https://www.asprs.org/wpcontent/uploads/pers/1983journal/jan/1983_jan_69-74.pdf

27 G. M. Foody: Remote Sens. Environ. 80 (2002) 185. https://doi.org/10.1016/S0034-4257(01)00295-4

28 J. Landis and G. Koch: Biometrics 33 (1977) 159. https://doi.org/10.2307/2529310

29 S. G. Plecida, A. I. Sfougaris, I. P. Ispikoudis, and V. P. Papanastasis: Int. J. Appl. Earth Obs. Geoinf. 26 (2014) 26. https://doi.org/10.1016/j.jag.2013.05.001

30 S. G. Heo, K. S. Kim, J. H. Ahn, J. S. Yoon, K. J. Lim, J. D. Choi, Y. C. Shin, and C. W. Lyou: J. KAGIS 10 (2007) 10. http://kiss.kstudy.com/thesis/thesis-view.asp?key=2899107.

31 D. K. Lee, H. Y. Yi, and E. Y. Kim: KOSERT 10 (2007) 120. http://kiss.kstudy.com/thesis/thesis-view. asp?key $=2664008$

32 E. C. Suh and Y. P. Kim: J. KIFR 14 (2010) 93. https://www.dbpia.co.kr/journal/ articleDetail?nodeId=NODE01488810\&language=ko_KR.

33 S. G. Jung, J. H. Oh, and K. H. Park: J. KAGIS 8 (2005) 145. http://kiss.kstudy.com/thesis/thesis-view. asp?key=2454851

\section{About the Authors}

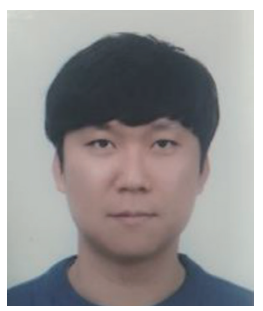

Jeongmook Park received his B.S., M.S., and Ph.D. degrees from Kangwon National University, Korea, in 2011, and 2013, and 2019, respectively. Since 2019, he has been a postdoctoral researcher at Kangwon National University. His research interests include forest spatial analysis using GIS and RS. (jm_park@kangwon.ac.kr)

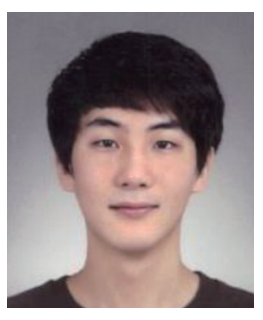

Woodam Sim received his B.S. and M.S. degrees from Kangwon National University, Korea, in 2015 and 2017, respectively, and is currently a Ph.D. candidate from the same institution. His research interests include forest structure analysis using GIS and RS. (swd1221@kangwon.ac.kr)

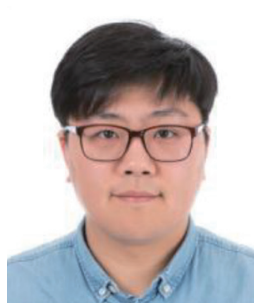

Jinwoo Park received his B.S., M.S., and Ph.D. degrees from Kangwon National University, Republic of Korea, in 2010, 2012, and 2017, respectively. He was a research scientist at the National Institute of Forest Science, Republic of Korea. Since 2018 and 2019, he has been an assistant professor at Kangwon National University. His research interests include forest management and timber yield regulation method. (pjw@kangwon.ac.kr)

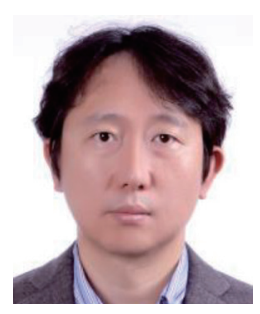

Jungsoo Lee received his B.S. degree from Kangwon National University, Republic of Korea, in 1998, and his M.S. and Ph.D. degrees from Tokyo University, Japan, in 2000 and 2003, respectively. Since 2006, he has been a professor at Kangwon National University. His research interests include GIS and remote sensing related to forest management. (jslee72@kangwon.ac.kr) 